\title{
Peripheral Retinal Imaging Biomarkers for Alzheimer's Disease: A Pilot Study
}

\author{
Lajos Csincsik $^{a, b}$ Thomas J. MacGillivrayc, ${ }^{c}$ Erin Flynn ${ }^{a, e}$ Enrico Pellegrini c, $f$ \\ Giorgos Papanastasiou $^{d}$ Neda Barzegar-Befroei ${ }^{b} \quad$ Adrienne Csutak $^{\text {b, }} \mathrm{g}$ \\ Alan C. Bird ${ }^{b}$ Craig W. Ritchie ${ }^{\mathrm{h}}$ Tunde Peto ${ }^{\mathrm{a}, \mathrm{i}}$ Imre Lengyel ${ }^{\mathrm{a}} \mathrm{b}$ \\ ${ }^{a}$ School of Medicine, Dentistry and Biomedical Science, Queen's University, Belfast, UK; ${ }^{b}$ UCL Institute of \\ Ophthalmology, London, UK; ' $V A M P I R E$ Project, Centre for Clinical Brain Sciences, University of Edinburgh, \\ Edinburgh, UK; ' Edinburgh Imaging, University of Edinburgh, Edinburgh, UK; ${ }^{\mathrm{e}}$ The George Washington University, \\ School of Medicine and Health Sciences, Washington, DC, USA; ${ }^{f}$ OPTOS plc, Dunfermline, UK; ${ }^{9}$ Department of \\ Ophthalmology, Faculty of Medicine, University of Debrecen, Debrecen, Hungary; ${ }^{\text {h}}$ Centre for Dementia Prevention, \\ University of Edinburgh, Edinburgh, UK; i NIHR Biomedical Research Centre, Moorfields Eye Hospital NHS \\ Foundation Trust and UCL, London, UK
}

\section{Keywords}

Alzheimer's disease - Age-related macular degeneration . Drusen - Vascular biomarker - Image grading · Imaging .

Peripheral retina $\cdot$ Fractal dimension $\cdot$ Tortuosity

\begin{abstract}
Purpose: To examine whether ultra-widefield (UWF) retinal imaging can identify biomarkers for Alzheimer's disease (AD) and its progression. Methods: Images were taken using a UWF scanning laser ophthalmoscope (Optos P200C AF) to determine phenotypic variations in 59 patients with $A D$ and 48 healthy controls at baseline (BL). All living participants were invited for a follow-up (FU) after 2 years and imaged again (if still able to participate). All participants had blood taken for genotyping at BL. Images were graded for the prevalence of age-related macular degeneration-like pathologies and retinal vascular parameters. Comparison between AD patients and controls was made using the Student $t$ test and the $X^{2}$ test. Results: Analysis at BL revealed a significantly higher prevalence of a hard drusen phenotype in the pe-
\end{abstract}

\section{KARGER}

(c) 2018 S. Karger AG, Basel

E-Mail karger@karger.com

www.karger.com/ore riphery of $A D$ patients $(14 / 55 ; 25.4 \%)$ compared to controls $(2 / 48 ; 4.2 \%)\left[X^{2}=9.9, \mathrm{df}=4, p=0.04\right]$. A markedly increased drusen number was observed at the 2-year FU in patients with $A D$ compared to controls. There was a significant increase in venular width gradient at $\mathrm{BL}$ (zone C: $8.425 \times 10^{-3}$ $\pm 2.865 \times 10^{-3}$ vs. $6.375 \times 10^{-3} \pm 1.532 \times 10^{-3}, p=0.008$; entire image: $8.235 \times 10^{-3} \pm 2.839 \times 10^{-3}$ vs. $6.050 \times 10^{-3} \pm 1.414 \times$ $\left.10^{-3}, p=0.004\right)$ and a significant decrease in arterial fractal dimension in $A D$ at $B L$ (entire image: $1.250 \pm 0.086$ vs. 1.304 $\pm 0.089, p=0.049$ ) with a trend for both at FU. Conclusions: UWF retinal imaging revealed a significant association between $A D$ and peripheral hard drusen formation and changes to the vasculature beyond the posterior pole, at $\mathrm{BL}$ and after clinical progression over 2 years, suggesting that monitoring pathological changes in the peripheral retina might become a valuable tool in AD monitoring.

(c) 2018 S. Karger AG, Basel

Craig Ritchie, Tunde Peto, and Imre Lengyel are senior authors. 


\section{Background}

Alzheimer's disease (AD) is characterised by the formation of extracellular amyloid beta $(\mathrm{A} \beta)$ plaques, the presence of intracellular neurofibrillary tangles in the brain [1], and altered levels of $A \beta$ and Tau in the cerebrospinal fluid [2]. However, definite diagnosis still only possible at post-mortem examination of autopsy samples [3]. Diagnosing and monitoring the progression of $\mathrm{AD}$ in the brain with the currently available methods is invasive, insensitive, and expensive, and often requires the use of radioactive isotopes $[4,5]$. Therefore, there is an urgent need for methods that can noninvasively, cost-effectively, and safely identify individuals at risk of disease progression.

The retina is part of the central nervous system, originates from the developing diencephalon, and shares structural and functional features with the brain [6-8]. Therefore, examination of macular images was suggested as a monitoring tool for the changes in the brain $[9,10]$. Changes in retinal morphology such as optic disc changes [11-14], retinal nerve fiber layer thinning [14-16], and loss of retinal ganglion cells [17-20] might be associated with $\mathrm{AD}$. A possible relationship between drusen formation in the macula and the severity of $\mathrm{AD}$ [21-24] has also been shown. Furthermore, due to the homology of the retinal and cerebral microvasculature, the condition of the retinal vasculature has been considered as a proxy for cerebral microvascular health [9]. Measuring geometric features of vessels visible on retinal imaging such as width and tortuosity is considered to infer the health of the retinal microvasculature, which reflects the state of the cerebral microvasculature. Studies have reported vascular abnormalities in the retina from the analysis of fundus camera images, including sparser arteriolar and venular networks and vessel caliber and tortuosity changes in the macula in $\mathrm{AD}$, but with conflicting outcomes due to varied protocol, small sample size, or variations in phenotypes considered as $\mathrm{AD}$ [25].

The macula occupies only a small proportion of the retina, and significant changes do occur in the peripheral retina with age $[26,27]$ and disease $[28-30]$. Technological advances brought about by the advent of the ultrawidefield scanning laser ophthalmoscope (UWF-SLO) now allow identification of peripheral retina abnormalities [27], similar to what can be observed in the macula [1], including retinal vascular parameters (RVPs) [31]. In fact, peripheral retina abnormalities do not need to directly correlate with changes in the macula; for example, drusen deposits within the peripheral retina have been observed in eyes with no macular deposits present [26, 27]. Here we investigated whether associations exist between retinal periphery changes and AD using UWF imaging, and we report, for the first time, retinal characteristics that might become candidate biomarkers for $\mathrm{AD}$ and its progression.

\section{Methods}

Ethics approval for the study protocol was obtained from the Ealing and West London Mental Health Trust Research Ethics Committee. The study complied with the Helsinki Declaration. Data collection took place at the West London Cognitive Disorders Treatment and Research Unit (WLCDTRU). Altogether, 59 patients and 48 controls entered this study. The controls were drawn from carers of index patients. Two patients had their data excluded from analysis due to suspected diagnosis of Lewy Body disease instead of AD based on the NINCDS-ADRDA criteria [32]. One patient's images were not gradable due to an inability to comply, giving a final analysis set of $56 \mathrm{AD}$ and 48 controls at baseline (BL), and $16 \mathrm{AD}$ and 16 controls at follow-up (FU). Medical history and standard socio-demographic factors such as age, gender, and education level were collected, as these may confound the relationship between $\mathrm{AD}$ and the presence of drusen. All study participants had blood drawn for the determination of genotype.

\section{Image Grading for Age-Related Macular Degeneration-Like Pathology}

Participants were imaged using the Optomap P200C UWFSLO (Optos Plc, Dunfermline, UK) operated by an imaging team from Optos, consisting of an imaging expert who was supervised by a clinician (T.P.) from the Moorfields Eye Hospital Reading Centre (MEHRC). The P200C uses red $(633 \mathrm{~nm})$ and green $(532$ $\mathrm{nm}$ ) lasers which are reflected off a large concave elliptical mirror to direct them to regions of the back of the eye that are inaccessible with other methods of fundus imaging. This instrument stores images in tiff format with dimensions 3,900 × 3,072 pixels.

Image grading was carried out by certified MEHRC graders masked to the participants' case-control status. Images were graded in random order without access to clinical information using the Optos V2 Vantage Dx Review 2.5.0.135 software that places a grading grid on an UWF image. This grid is based on the original definition of a standard macular grid defined by the distance between the centres of the optic nerve head and the fovea [33]; extended by 2 further zones, i.e., zone 4 for the mid-periphery, and zone 5 for the far periphery. Drusen size was measured using established standard measuring tools and lesion sizes [33] on unprojected images. Only abnormalities resembling age-related pathologies such as hard and soft drusen, retinal pigment epithelial changes, pigment epithelial detachment, geographic atrophy, and choroidal neovascularisations were graded [33].

We previously reported that UWF images were gradable in the macula, even on images that fell short of grading standards on conventional fundus images [27]. This was due to the SLO instrument being less susceptible to media opacities than conventional fundus imaging. Occasionally, grading on $>1$ image had to be carried out from the same eye, due to blinking during acquisition (which ob- 
Fig. 1. Grading of vascular parameters on UWF imaging. Dashed circles represent grading zones $\mathrm{B}$ : $0.5-1 \mathrm{OD}$ diameter. C: 1-2 OD diameter. Turquoise lines, vascular fractal dimension; green dots, branching points; red line, arteriole; blue line, venule.

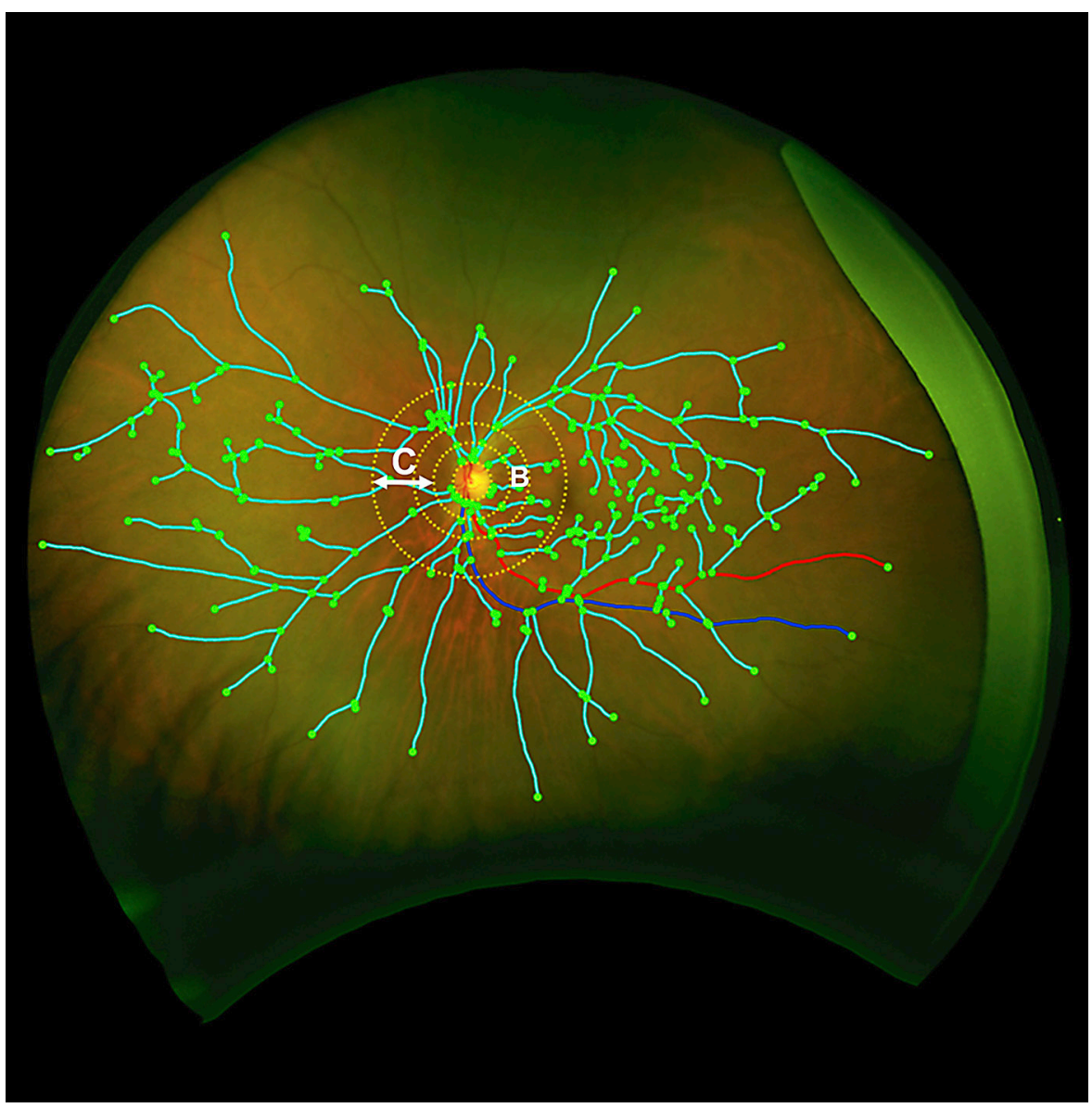

scures parts of the retina) or artefacts caused by an individual experiencing difficulty in opening their eyelids. The study was planned to be conducted without mydriasis, with the option for using dilation with tropicamide $1 \%$ (Alcon) if needed. Interestingly, dilation was necessary in all AD patients to enable goodquality retinal photographs to be taken, while only 7 of the controls required dilation.

Analysis was undertaken in SPSS (Rel. 14.0.0. 2007; SPSS Inc., Chicago, IL, USA). An association between AD status and the presence of drusen in 4 states/locations was investigated using the $\chi^{2}$ test. Exploration of potential confounders (i.e., clinical, genetic, and sociodemographic) was undertaken and adjusted following nominal regression analysis, given the categorical nature of the exposure and outcomes. Potential confounders were selected for regression analysis if their association with both the exposure and principal outcome generated a $p$ value of $<0.1$.

\section{Image Analysis for RVPs}

Prior to the measurement of RVPs, the UWF images were assessed by a trained operator who judged each image in terms of the available area of retina imaged and the contrast between the visible vasculature and retinal background. Eyelashes can sometimes obscure large parts of the retina, preventing RVP measurements. Poor image contrast, resulting from difficulties with the acquisition (e.g., inexact participant positioning), means the computa- tional analysis of vessels is sometimes not achievable. After assessment, images deemed acceptable for analysis were stereographically projected, to compensate for distortions due to the retinal curvature and to enable the subsequent measurements made on the images in pixels to be converted to millimetre equivalents on the retina [34]. The operator then identified the region of interest in each image by masking out shadows caused by any eyelashes and areas of low contrast at the image edges, before enacting automatic segmentation of the vasculature [31]. Manual refinement removed artefacts (i.e., spurious vessel detections) and separated out the arteriolar and venular components of the vascular tree by labelling vessels and marking crossing points by hand.

For RVP analysis, we placed the conventional set of circular measurement zones commonly used for fundus camera imaging on the projected UWF images [25]. This was zone $\mathrm{B}$, which is a ring 0.5-1 OD in diameter away from the centre of the OD, and zone C, which is a ring extending from the OD boundary to a 2-OD diameter away (Fig. 1). We also performed novel analysis that is only possible with UWF imaging by utilising the whole area of the visible retina permitted by each image, from the OD boundary out towards the periphery. RVPs were measured in these zones using software specially designed to handle UWF imaging, VAMPIRE for UWFSLO (v1, Universities of Edinburgh and Dundee, UK), and were in agreement with previously reported analysis of fundus camera imaging [35], except for the novel parameters described below. 


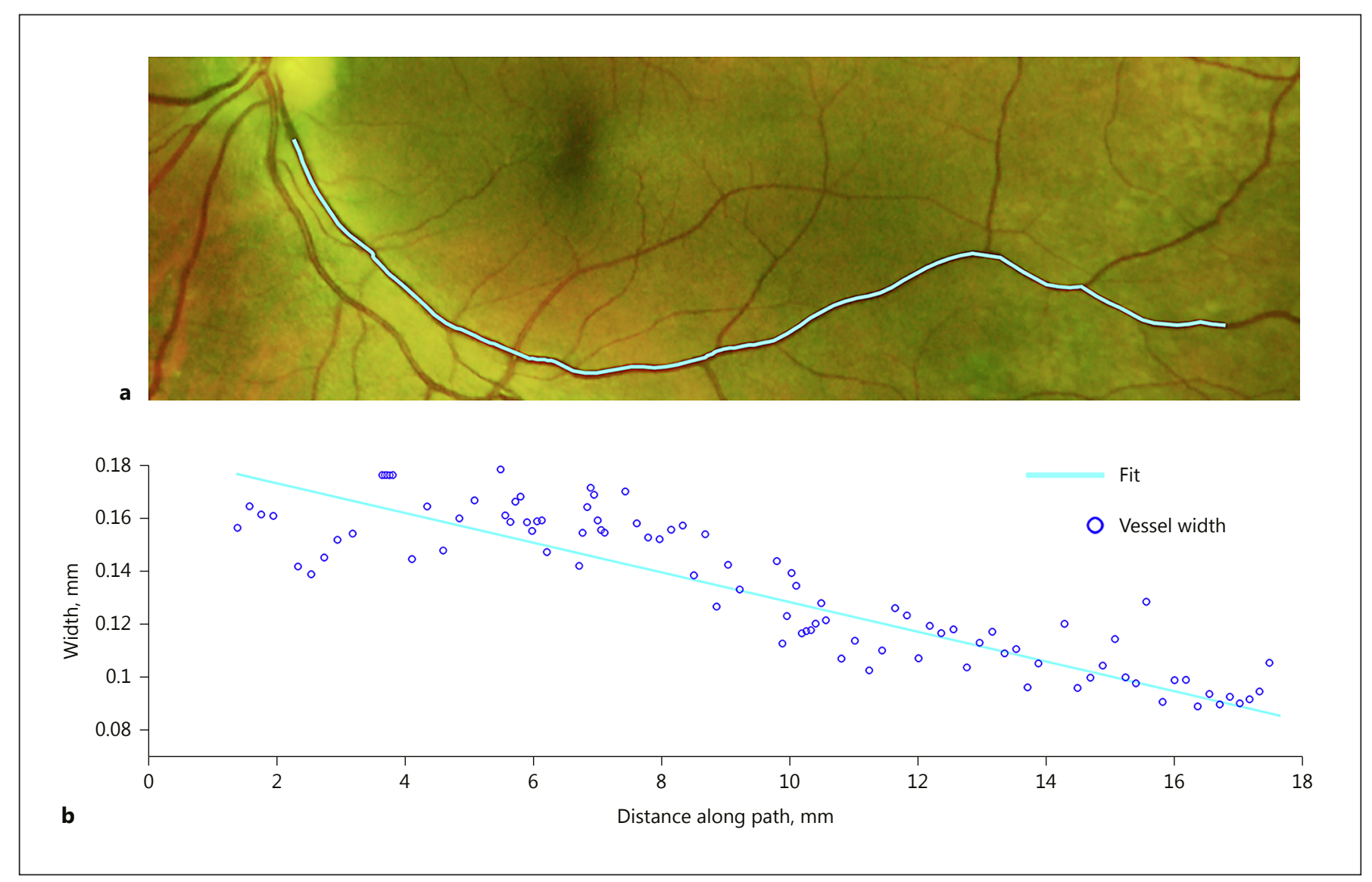

Fig. 2. Determination of vascular gradient. a Turquoise line shows an identified venule. b Blue circles are measured vascular width; turquoise line depicts best fit.

\section{Novel Parameters}

The tortuosity of arterioles and venules (TORTa and TORTv, respectively) were measured [36] for the large vessels originating in zone B identified visually by the operator, who selected the path followed by these vessels into zone $\mathrm{C}$ or as far as the image permitted towards the periphery (entire image). Tortuosity measurements per quadrant were collected, using 2 segregating lines to divide the retina, one through the centre of the OD and fovea, and the second perpendicular to the first and through the OD. The parameters recorded included "main," which corresponded to the tortuosity of the principal path of the main vessel, and "total," which involved calculating the median tortuosity for all the vessel segments that were measured.

Further analysis of the main vessels ( 1 arteriole and 1 venule per quadrant, as selected by the operator) was conducted by measuring vessel calibre at regular intervals (every 4 pixels) along the entire vessel path (Fig. 2a). Quantifying how the width diminishes as the vessel extends out towards the periphery was achieved by fitting a straight line to the calibre measurements (Fig. 2b). The gradient of the straight-line fit for the main vessels gives the width gradient (WG), i.e., arterial WG (WGa) and venular WG (WGv), respectively. An abnormal decline in vessel width as reflected in the evaluation of WG may indicate irregular vessel health.

\section{Results}

\section{Genotyping and Background Factors}

The following factors were associated with AD: ApoE4 RS429358 status $\left(\chi^{2}=4.9, \mathrm{df}=2, p=0.09\right)$, a history of transient ischemic attack (TIA; $\chi^{2}=3.1, \mathrm{df}=1, p=0.08$ ), and being an ex-smoker $\left(\chi^{2}=5.6, \mathrm{df}=2, p=0.06\right)$. Patients with AD were slightly older (79.2 [SD 8.4] years) than controls (70.7 [SD 10.4] years) $(p<0.0001)$. Peripheral retinal clinical findings were associated with a history of heart failure $\left(\chi^{2}=8.1, \mathrm{df}=4, p=0.09\right)$, stroke $\left(\chi^{2}=10.1, \mathrm{df}=4\right.$, $p=0.04)$, and TIA $\left(\chi^{2}=8.1, \mathrm{df}=4, p=0.09\right)$. Given the strength of the association between age and dementia, and the co-occurrence of TIA history with both dementia status and retinal changes, the phenotyping model was reanalyzed, taking these variables into account. This adjusted analysis demonstrated a very strong association between variability on peripheral clinical findings and $\mathrm{AD}$ (likelihood ratio test, $\chi^{2}=32.3, \mathrm{df}=12, p=0.001$ ). 
Fig. 3. Hierarchical phenotyping for AMDlike pathologies in $\mathrm{AD}$. $\mathrm{AD}$ patients were significantly more likely to be phenotyped as hard drusen in the periphery compared to controls $(14 / 55$ [25.4\%] vs. $2 / 48[4.2 \%]$; $\left.\chi^{2}=9.9, \mathrm{df}=4\right) .{ }^{*} p=0.04$.

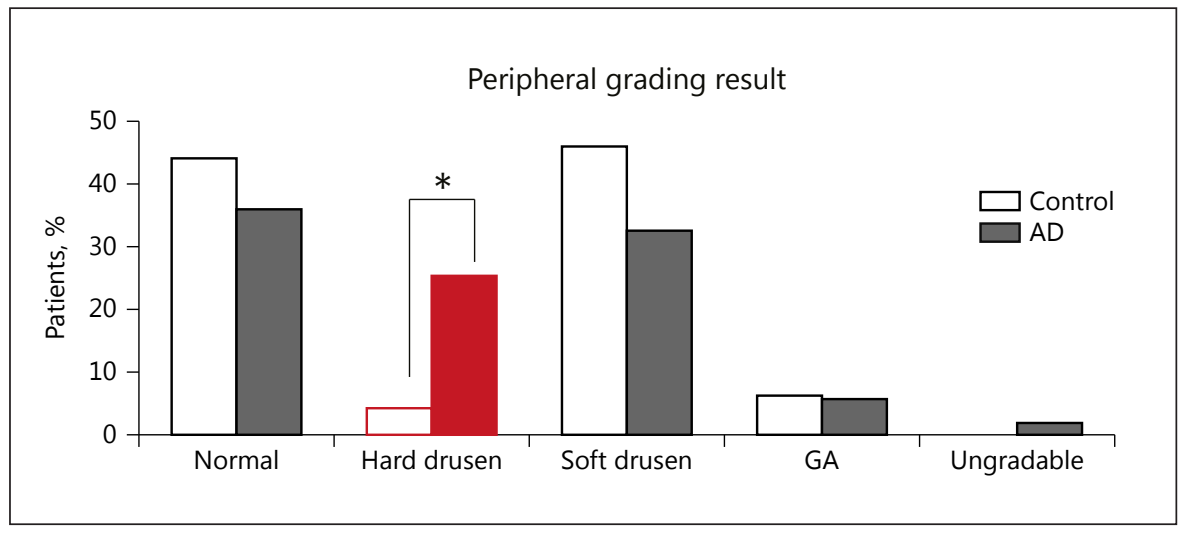

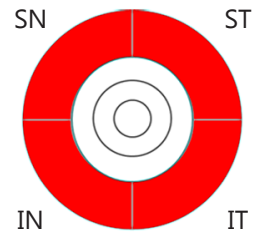
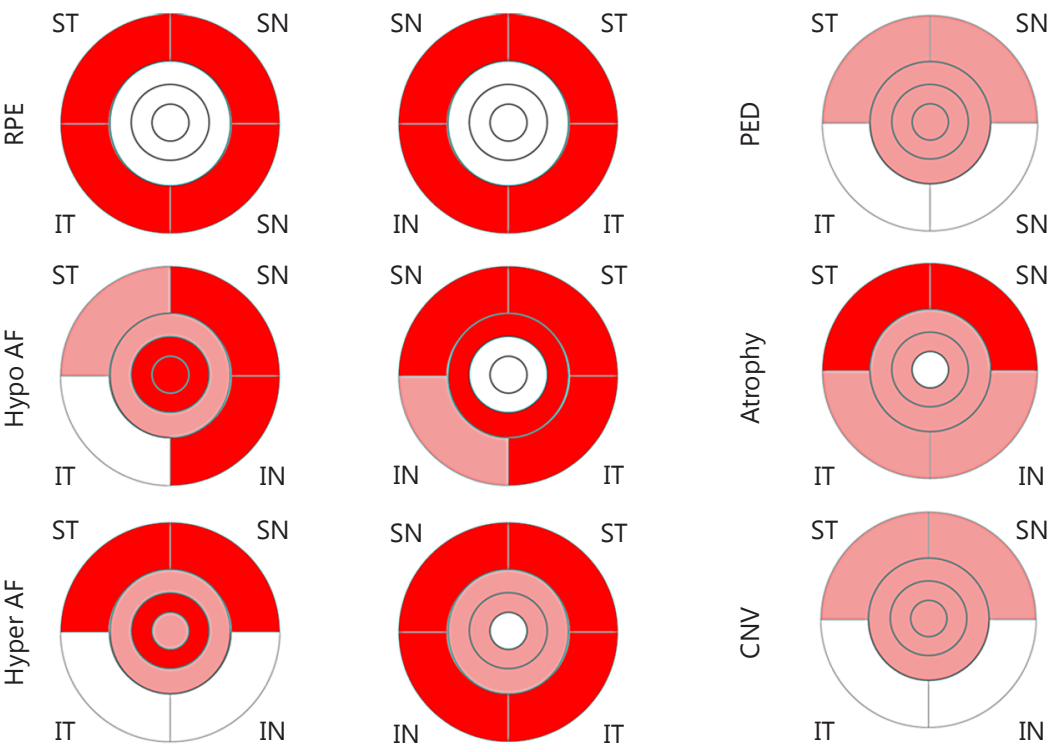
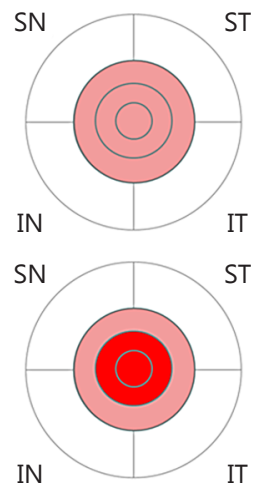

T

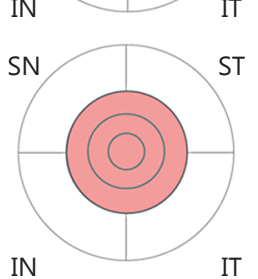

Fig. 4. Zone-specific grading for AMD-like pathologies. Red, an increased AD prevalence; white, no difference; pink, intermediate difference. SN, superior nasal; IN, inferior nasal; IT, inferior temporal; ST, superior temporal; RPE, retinal pigment epithelium; Hyper AF, Hyper-autofluorescence; Hypo AF, Hypo-autofluorescence; PED, pigment epithelial detachment; CNV, choroidal neovascularization.

\section{Image Grading for Age-Related Macular}

Degeneration-Like Pathology

On grading for age-related macular degeneration (AMD)-like lesions, the $\mathrm{AD}$ patient group showed an increased incidence of AMD compared to controls (4 vs. 1, respectively), but significance could not be calculated given the small numbers in each group.

Next, we determined the clinical phenotype of the peripheral retina changes. We applied a hierarchical phenotyping protocol: those with hard drusen only were as- signed to the hard drusen phenotype. Those with both hard and soft drusen were designated as the soft drusen phenotype. Eyes were phenotyped as atrophy even if they had hard or soft drusen or pigment changes. Based on this phenotyping, $\mathrm{AD}$ patients were significantly more likely to be phenotyped as hard drusen in the periphery $(14 / 55$ [25.4\%] of AD patients vs. $2 / 48$ [4.2\%] of controls; $\chi^{2}=$ $9.9, \mathrm{df}=4, p=0.04)$. No significant differences could be found in the soft drusen, pigment changes, and atrophy phenotypes (Fig. 3). 

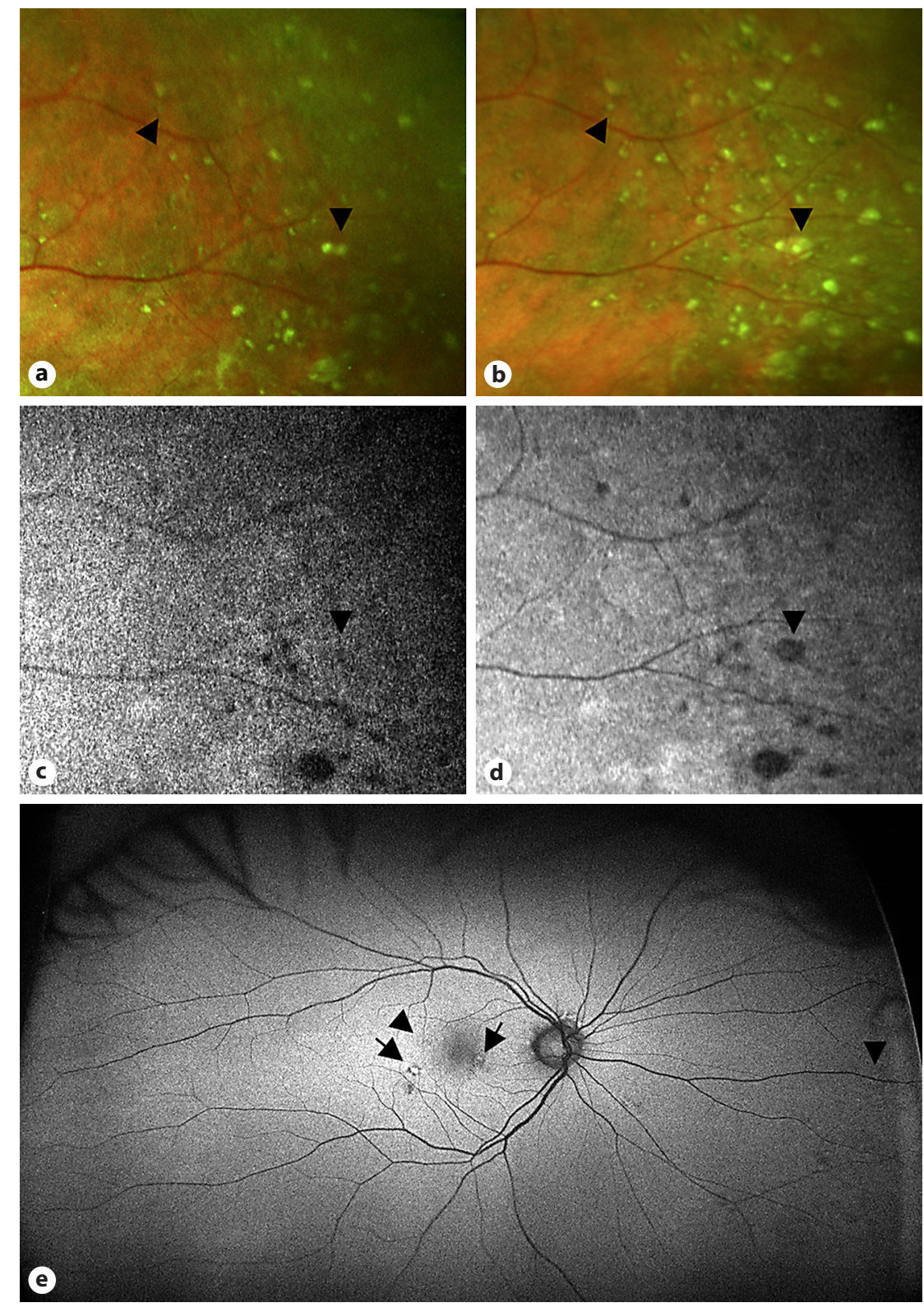

Fig. 5. Representative colour (a, b) and corresponding autofluorescence $(\mathrm{AF})(\mathbf{c}, \mathbf{d})$ images at the peripheral retina for progression in an $\mathrm{AD}$ eye that occurred during the 2 years till followup. a, c At baseline. b, d At follow-up. Black arrowheads denote progression. e, $\mathbf{f}$ UWF images representative of AF progression. Arrows, progression to atrophy; arrowheads, progression to hyper-AF.

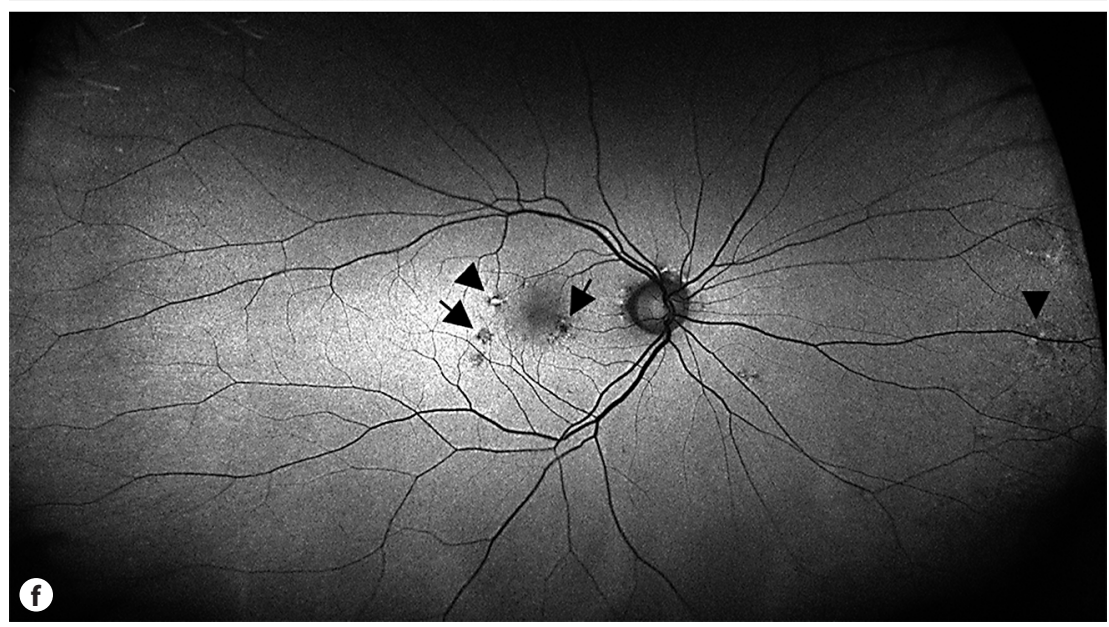


Table 1. Comparison of width gradient values in $\mathrm{AD}$ cases and controls

\begin{tabular}{lllllll}
\hline Parameter & $\begin{array}{l}\text { AD cases } \\
(n=13) \\
\text { at BL }\end{array}$ & $\begin{array}{l}\text { Controls } \\
(n=14) \\
\text { at BL }\end{array}$ & $p$ & $\begin{array}{l}\text { AD cases } \\
(n=9) \\
\text { at FU }\end{array}$ & $\begin{array}{l}\text { Controls } \\
(n=14) \\
\text { at FU }\end{array}$ & $p$ \\
\hline Zone C & & & & & \\
WGa-ST & $4.850(3.358)$ & $5.378(3.107)$ & 0.605 & $3.292(1.872)$ & $5.355(2.617)$ & $\mathbf{0 . 0 2 2}$ \\
WGa-IT & $5.325(5.534)$ & $4.030(2.193)$ & 0.336 & $6.608(6.322)$ & $4.814(4.171)$ & 0.333 \\
WGa-IN & $8.800(8.156)$ & $6.138(5.489)$ & 0.226 & $10.445(8.021)$ & $6.482(8.150)$ & 0.195 \\
WGa-SN & $5.958(4.249)$ & $4.847(3.450)$ & 0.382 & $4.483(4.044)$ & $3.294(2.871)$ & 0.362 \\
WGa-all & $6.170(3.099)$ & $5.013(2.151)$ & 0.152 & $6.175(2.549)$ & $5.410(2.531)$ & 0.411 \\
WGv-ST & $7.495(3.310)$ & $6.708(3.852)$ & 0.477 & $6.433(1.836)$ & $6.323(3.035)$ & 0.909 \\
WGv-IT & $7.395(3.947)$ & $6.174(1.589)$ & 0.180 & $11.033(11.547)$ & $6.181(2.740)$ & 0.178 \\
WGv-IN & $8.542(3.968)$ & $7.465(3.282)$ & 0.341 & $11.255(6.140)$ & $7.836(4.607)$ & 0.082 \\
WGv-SN & $10.730(7.677)$ & $5.004(2.865)$ & $\mathbf{0 . 0 0 5}$ & $8.055(8.005)$ & $5.305(2.495)$ & 0.290 \\
WGv-all & $8.425(2.865)$ & $6.375(1.532)$ & $\mathbf{0 . 0 0 8}$ & $9.275(4.999)$ & $6.400(1.728)$ & 0.077 \\
\hline Entire image & & & & & & \\
WGa-ST & $4.358(3.302)$ & $5.322(3.100)$ & 0.336 & $3.133(1.583)$ & $4.991(2.639)$ & $\mathbf{0 . 0 1 5}$ \\
WGa-IT & $5.135(5.179)$ & $3.809(2.234)$ & 0.298 & $6.542(6.290)$ & $4.319(3.486)$ & 0.199 \\
WGa-IN & $8.430(7.698)$ & $5.714(4.795)$ & 0.181 & $10.327(7.816)$ & $7.505(6.487)$ & 0.284 \\
WGa-SN & $5.605(5.605)$ & $4.884(3.562)$ & 0.571 & $4.333(4.041)$ & $2.978(2.964)$ & 0.298 \\
WGa-all & $5.835(2.976)$ & $4.970(1.948)$ & 0.275 & $6.017(2.571)$ & $5.124(2.368)$ & 0.320 \\
WGv-ST & $7.300(4.031)$ & $6.533(3.143)$ & 0.471 & $6.358(1.800)$ & $6.245(3.091)$ & 0.909 \\
WGv-IT & $7.240(3.939)$ & $5.888(1.713)$ & 0.136 & $11.000(11.564)$ & $6.000(2.796)$ & 0.167 \\
WGv-IN & $8.384(4.031)$ & $7.091(3.085)$ & 0.246 & $10.773(6.187)$ & $7.464(4.534)$ & 0.090 \\
WGv-SN & $10.495(7.707)$ & $4.796(2.769)$ & $\mathbf{0 . 0 0 6}$ & $7.664(7.814)$ & $5.129(2.412)$ & 0.316 \\
WGv-all & $8.235(2.839)$ & $6.050(1.414)$ & $\mathbf{0 . 0 0 4}$ & $8.992(4.833)$ & $6.264(1.695)$ & 0.082 \\
\hline & & & & & \\
\hline
\end{tabular}

The values are mean (SD). Bold type denotes significant differences. $p$ values were calculated by independent $t$ test. AD, Alzheimer's disease; BL, baseline; FU, follow-up; WGa, arterial width gradient; WGv, venular width gradient; all, all quadrants; ST, superior temporal quadrant; IT, inferior temporal quadrant; IN, inferior nasal quadrant; SN, superior nasal quadrant.

Grid-specific appearance of different pathological signs were also plotted based on our previous analysis [27]. Due to the difficulty for the patients to open their eyelids wide, and therefore our inability to generate good quality images in zone 5, we only analyzed zones 1-4. Then we subtracted the incidences of the appearance of phenotypic features of $\mathrm{AD}$ patients from those at the same geographic location in controls, and plotted these differences in Figure 4 (those with a higher prevalence in $\mathrm{AD}$ were labelled red, white indicates no difference, and pink an intermediate small difference). This semi-quantitative assessment highlighted that, in $\mathrm{AD}$, most of the increased incidences of pathological changes were associated with the superior and/or nasal part of the retina (Fig. 4).

At FU, only $16 \mathrm{AD}$ and 16 controls could participate, and therefore we could only make a qualitative assessment of their drusen load. There were a few more visible drusen detected in controls at the 2-year FU; however, in the $\mathrm{AD}$ eyes, the increase in drusen numbers was consistently higher than in controls (Fig. 5).

\section{RVP Measurements}

Of the 32 participants with a FU, 27 participants (13 $\mathrm{AD}$ patients and 14 controls) could be analyzed at $\mathrm{BL}$, and 23 (9 AD and 14 controls) at FU. Analyzing zone B (Fig. 1) revealed no significant differences between controls and $\mathrm{AD}$ at $\mathrm{BL}$ or at $\mathrm{FU}$, and no progression (a comparison of BL with FU) could be detected (results not shown).

Analyzing zone $\mathrm{C}$ (Fig. 1) revealed increases in the WGv when the $\mathrm{AD}$ group was compared to controls at $\mathrm{BL}$ $\left(8.42 \times 10^{-3} \pm 2.80 \times 10^{-3}\right.$ and $6.37 \times 10^{-3} \pm 1.53 \times 10^{-3}$, respectively; $p=0.008$ ). This appeared to be driven by the increase in WGv in the superior nasal quadrant $(10.73 \times$ $10^{-3} \pm 7.68 \times 10^{-3}$ and $5.00 \times 10^{-3} \pm 2.86 \times 10^{-3}$, respectively; $p=0.005$ ) (Table 1 ). In contrast, there were no differences in $\mathrm{WGa}$ at $\mathrm{BL}$, but there was a significant decrease in $\mathrm{WGa}$ in the superior temporal quadrant in $\mathrm{AD}$ 
Table 2. Comparison of fractal dimension values in $\mathrm{AD}$ cases and controls

\begin{tabular}{cllllll}
\hline Parameter & $\begin{array}{l}\text { AD cases } \\
(n=13) \\
\text { at BL }\end{array}$ & $\begin{array}{l}\text { Controls } \\
(n=14) \\
\text { at BL }\end{array}$ & $p$ & $\begin{array}{l}\text { AD cases } \\
(n=9) \\
\text { at FU }\end{array}$ & $\begin{array}{l}\text { Controls } \\
(n=14) \\
\text { at FU }\end{array}$ & $p$ \\
\hline $\begin{array}{l}\text { Zone C } \\
\text { FDa }\end{array}$ & $1.166(0.063)$ & $1.197(0.061)$ & 0.112 & $1.170(0.051)$ & $1.194(0.062)$ & 0.254 \\
FDv & $1.190(0.066)$ & $1.191(0.057)$ & 0.968 & $1.190(0.069)$ & $1.179(0.066)$ & 0.666 \\
\hline $\begin{array}{l}\text { Entire image } \\
\text { FDa }\end{array}$ & $1.250(0.086)$ & $1.304(0.089)$ & $\mathbf{0 . 0 4 9}$ & $1.262(0.064)$ & $1.311(0.085)$ & 0.092 \\
FDv & $1.307(0.081)$ & $1.323(0.065)$ & 0.479 & $1.310(0.081)$ & $1.329(0.069)$ & 0.469 \\
\hline
\end{tabular}

The values are mean (SD). Bold type denotes significant differences. $p$ values were calculated by independent $t$ test. AD, Alzheimer's disease; BL, baseline; FU, follow-up; FDa, arteriolar fractal dimension; FDv, venular fractal dimension.

patients versus controls at FU $\left(3.29 \times 10^{-3} \pm 1.87 \times 10^{-3}\right.$ vs. $5.35 \times 10^{-3} \pm 2.61 \times 10^{-3}$ respectively; $p=0.022$ ) (Table 1). Despite these changes, no statistically significant progression could be detected in zone C (data not shown), possibly due to the small numbers.

The most consistent differences between AD patients and controls were observed when the entire image was considered; we detected a significant difference in arterial fractal dimension (FDa) at BL ( $1.25 \pm 0.08$ and $1.30 \pm$ 0.09 respectively; $p=0.049)$ with a trend at $\mathrm{FU}(p=0.092)$ (Table 2). In addition, the observed significant increase in WGv in zone $\mathrm{C}$ remained significantly higher in $\mathrm{AD}$ patients compared to controls when all quadrants were considered $\left(8.23 \times 10^{-3} \pm 2.84 \times 10^{-3}\right.$ vs. $6.05 \times 10^{-3} \pm 1.41 \times$ $\left.10^{-3} ; p=0.004\right)$. This difference was most likely driven by the significant increase in $\mathrm{WGv}$ in the superior nasal quadrant $\left(10.49 \times 10^{-3} \pm 7.70 \times 10^{-3}\right.$ vs. $4.79 \times 10^{-3} \pm 2.77$ $\left.\times 10^{-3} ; p=0.006\right)$. The significant decrease in WGa in AD patients in zone $\mathrm{C}$ in the superior temporal quadrant remained when the entire image was analyzed $\left(3.13 \times 10^{-3}\right.$ $\pm 1.58 \times 10^{-3}$ vs. $\left.4.99 \times 10^{-3} \pm 2.63 \times 10^{-3} ; p=0.015\right)(\mathrm{Ta}-$ ble 1 ). As for zone $C$, no statistically significant progression could be detected in RVPs on the whole image (data not shown).

\section{Discussion}

Previous studies that examined retinal pathologies in AD concentrated on the macula and investigated the potential associations between $\mathrm{AMD}$ and $\mathrm{AD}$. Using fundus camera images, several of these studies suggested that the 2 diseases share some pathomechanisms as well as envi- ronmental and genetic risk factors [21,37-39]. However, such associations are still being debated [40]. The macula is only a small portion of the retina, and AMD-like pathologies are widespread at the peripheral retina, even in the absence of macular changes, so we examined the entire retina of patients with $\mathrm{AD}$. We analyzed the UWF images for AMD-like pathologies as well as retinal vascular changes, and compared these to controls with no history of dementia. Our results indicate that analyzing the peripheral retina could yield potential biomarkers for $\mathrm{AD}$ and its progression, both in drusen deposition and in vascular characteristics.

In the peripheral retina, hard drusen accumulation, especially in the superior nasal quadrant, was significantly associated with positive $\mathrm{AD}$ status $(p=0.04)$ at $\mathrm{BL}$ image grading. When results were adjusted for age and a history of TIA, the association between the peripheral hard drusen phenotype and $\mathrm{AD}$ increased in significance $(p=$ 0.001 ). At the 2-year FU examination conducted on those who were still able to comply, we found that there were more areas associated with drusen deposition in $\mathrm{AD}$ but we also observed a consistently higher increase in drusen numbers in all patients when compared to controls. The increase in drusen number in the control group was expected with the advancement of age [41].

In addition to peripheral hard drusen accumulation, changes in some of the RVPs were also associated with $\mathrm{AD}$ in our study. We were able to extend the vascular analysis beyond the $\mathrm{B}$ and $\mathrm{C}$ zones conventionally employed for standard fundus camera imaging. We analyzed, for the first time, the entire visible image area obtained with UWF-SLO. Previous studies investigating zones $\mathrm{B}$ and $\mathrm{C}$ on conventional fundus camera images 
found several significant differences in RVPs in zone B $[10,35,42]$. While we measured comparable RVPs (Table 1) from the UWF imaging, we did not detect such differences in $\mathrm{AD}$ patients and controls. In zone $\mathrm{C}$, based on the previous reports, the most consistent RVP outcome was a decrease in retinal fractal dimensions in $\mathrm{AD}[10,35$, 42]. We did not find evidence of changes in FD in zone $C$ from our measurements. The lack of observed effect in previous studies could have been due to the use of patients with more advanced $\mathrm{AD}$, but possibly also due to the lower resolution in UWF images than in fundus color images (i.e., $10-15$ vs. approx. $7 \mu \mathrm{m}$ ). A direct comparison of these imaging modalities would help clarify this issue in the future. Despite the lack of measurable FD differences in zone $\mathrm{C}$, we found a decreased FDa when the analysis was extended to the entire image, i.e., encompassing the peripheral retina (Table 2). Recent studies correlated retinal FD with cerebral cortical volumes and found a positive correlation with FDa [43]. As decreased cortical volume has been associated with $\mathrm{AD}$ [44-46], changes in $\mathrm{FDa}$ in the peripheral retina might be a new prospective biomarker and a surrogate for $\mathrm{AD}$-associated atrophy.

There are conflicting outcomes in the literature for retinal vascular tortuosity measured in zone C. Frost et al. [35] reported decreased TORTv but no change in TORTa. Cheung et al. [10] found increased TORTa and TORTv. Williams et al. [42] detected a decrease in TORTa only. From our measurements, we did not find evidence of any differences in tortuosity between $\mathrm{AD}$ and control in zone $\mathrm{C}$, nor did we find a difference when the entire image was considered. This inconsistency of the studies is likely due to the different algorithms used for calculating tortuosity and the number of samples used to construct the final summative parameter. Whether tortuosity is a possible surrogate for $\mathrm{AD}$ therefore remains questionable, as a protocol for measuring this parameter is yet to be optimized.

Vascular WG measurement is a novel parameter to assess changes in the retinal vasculature. For this measurement, we analyzed the main vessels over a longer path distance than is achievable with standard fundus camera imaging. As WG indicates how the diameter of a vessel thins from the more central to the peripheral areas, it might be directly proportional to blood flow. We found that there is a significant increase in WGv in AD. Given that we did not find significant differences in vascular calibres in zone $\mathrm{B}$ between the $\mathrm{AD}$ and control groups, the increased WGv in zone $\mathrm{C}$ and beyond indicates a more pronounced thinning of venules towards to the peripheral retina. The result of this thinning is likely to be a de-

Peripheral Retinal Imaging Biomarkers for Alzheimer's Disease: A Pilot Study creased blood flow in AD. Taken together, the increased WGv and lower FDa represent a less complex and sparser vascular bed, leading to decreased oxygenation and availability of nutrients as well as sub-optimal clearance in the peripheral retina. The thinner veins and a less complex arterial network may generate an environment that is more conducive to degeneration, and might even be related to the increased drusen accumulation and progression we have observed in AD. It would be interesting to study whether WGs in the brain vasculature correlate with increased plaque deposition in $\mathrm{AD}$.

One of the major limitations of all $\mathrm{AD}$ studies on the eye is the small number of participants enrolled [25]. Although the sample size in our study was modest, a genotypic association between AD and the ApoE4 RS429358 allele type was demonstrated, suggesting that the selection process was representative of $\mathrm{AD}$ [47]. As in previous studies $[21,22]$, we observed a potential association between $\mathrm{AD}$ and $\mathrm{AMD}$ based on the appearance of end-stage AMD in the macula. However, we believe that the small sample size does not allow this produce a statistically meaningful conclusion. Another limitation was that we conducted multiple testing for associations with different types of eye pathology, which may have led to a type 1 error, and the relatively small sample size to a type 2 error. In addition, although the controls were deemed to not have AD according to the NINCDS-ADRDA criteria, we cannot rule out that they could have had pre-clinical AD.

In conclusion, based on the data we presented in this paper, we are promoting the possibility that increased peripheral hard drusen deposition, decreased FDa, and increased WGv are potential imaging-derived biomarkers of $\mathrm{AD}$. To be a reasonable marker of early disease, presymptomatic people or early symptomatic (pre-dementia) patients would need to be followed up over several years to determine the predictive value of the peripheral retina findings with regard to the development of dementia. Moreover, associations with other putative markers of $\mathrm{AD}$ would be illuminating rather than relying solely on associations with the prominent clinical phenotype of AD. Prospective studies with a greater number of patients and earlier disease stages (e.g., the Deep and Frequent Phenotyping Study [48] and the PREVENT Dementia Cohort [49]) will help elucidate whether this can be verified in a larger cohort. If the observations made in this initial study remain robust, then routine UWF imaging might achieve an earlier and thereby clinically opportune and cost-effective method for monitoring the progression of $\mathrm{AD}$ and identifying individuals at a high risk of developing AD. 


\section{Acknowledgements}

The authors would like to thank P. Ndhlovu, D. Wilson, A. Holborow, B. Goud, N. Cheesman, and B. Corridan for their invaluable help with the study, and Gavin Robertson for generating Figure 1. The research was supported by the Bill Brown Charitable Trust Senior Research Fellowship, Moorfields Eye Hospital Special Trustees, and the Mercer Fund from Fight for Sight (I.L). Lajos Csincsik is supported by an unrestricted PhD studentship from Optos Plc.

\section{Disclosure Statement}

The authors have no conflicts of interest to disclose.

\section{References}

1 Scahill RI, Schott JM, Stevens JM, Rossor MN, 12 Danesh-Meyer HV, Birch H, Ku JY, Carroll S, Fox NC: Mapping the evolution of regional atrophy in Alzheimer's disease: unbiased analysis of fluid-registered serial MRI. Proc Natl Acad Sci USA 2002;99:4703-4707.

2 Hampel H, Burger K, Teipel SJ, Bokde AL, Zetterberg $\mathrm{H}$, Blennow K: Core candidate neurochemical and imaging biomarkers of Alzheimer's disease. Alzheimers Dement 2008;4:38-48.

3 Braak H, Braak E: Frequency of stages of Alzheimer-related lesions in different age categories. Neurobiol Aging 1997;18:351-357.

-4 Alzheimer's Association: 2013 Alzheimer's disease facts and figures. Alzheimers Dement 2013;9:208-245.

5 Blennow K, de Leon MJ, Zetterberg H: Alzheimer's disease. Lancet 2006;368:387-403.

6 Hughes S, Yang H, Chan-Ling T: Vascularization of the human fetal retina: roles of vasculogenesis and angiogenesis. Invest Ophthal$\mathrm{mol}$ Vis Sci 2000;41:1217-1228.

7 Chan-Ling T, McLeod DS, Hughes S, Baxter L, Chu Y, Hasegawa T, Lutty GA: Astrocyteendothelial cell relationships during human retinal vascular development. Invest Ophthalmol Vis Sci 2004;45:2020-2032.

8 Hardy P, Varma DR, Chemtob S: Control of cerebral and ocular blood flow autoregulation in neonates. Pediatr Clin North Am 1997;44: 137-152.

-9 Patton N, Aslam T, Macgillivray T, Pattie A, Deary IJ, Dhillon B: Retinal vascular image analysis as a potential screening tool for cerebrovascular disease: a rationale based on homology between cerebral and retinal microvasculatures. J Anat 2005;206:319-348.

10 Cheung CY, Ong YT, Ikram MK, Ong SY, Li $\mathrm{X}$, Hilal S, Catindig JA, Venketasubramanian N, Yap P, Seow D, Chen CP, Wong TY: Microvascular network alterations in the retina of patients with Alzheimer's disease. Alzheimers Dement 2014;10:135-142.

-11 Bambo MP, Garcia-Martin E, Gutierrez-Ruiz F, Pinilla J, Perez-Olivan S, Larrosa JM, Polo V, Pablo L: Analysis of optic disk color changes in Alzheimer's disease: a potential new biomarker. Clin Neurol Neurosurg 2015;132:68-73. Gamble G: Reduction of optic nerve fibers in patients with Alzheimer disease identified by laser imaging. Neurology 2006;67:1852-1854.

13 Tsai CS, Ritch R, Schwartz B, Lee SS, Miller NR, Chi T, Hsieh FY: Optic nerve head and nerve fiber layer in Alzheimer's disease. Arch Ophthalmol 1991;109:199-204.

14 Iseri PK, Altinas O, Tokay T, Yuksel N: Relationship between cognitive impairment and retinal morphological and visual functional abnormalities in Alzheimer disease. J Neuroophthalmol 2006;26:18-24.

15 Berisha F, Feke GT, Trempe CL, McMeel JW, Schepens CL: Retinal abnormalities in early Alzheimer's disease. Invest Ophthalmol Vis Sci 2007;48.

16 Coppola G, Di Renzo A, Ziccardi L, Martelli F, Fadda A, Manni G, Barboni P, Pierelli F, Sadun AA, Parisi V: Optical coherence tomography in Alzheimer's disease: a metaanalysis. PLoS One 2015;10:e134750.

17 La Morgia C, Ross-Cisneros FN, Koronyo Y, Hannibal J, Gallassi R, Cantalupo G, et al: Melanopsin retinal ganglion cell loss in Alzheimer disease. Ann Neurol 2016;79:90-109.

18 Blanks JC, Torigoe Y, Hinton DR, Blanks RH: Retinal pathology in Alzheimer's disease. I. Ganglion cell loss in foveal/parafoveal retina. Neurobiol Aging 1996;17:377-384.

19 Sadun AA, Bassi CJ: Optic nerve damage in Alzheimer's disease. Ophthalmology 1990;97: 9-17.

20 Blanks JC, Schmidt SY, Torigoe Y, Porrello $\mathrm{KV}$, Hinton DR, Blanks RH: Retinal pathology in Alzheimer's disease. II. Regional neuron loss and glial changes in GCL. Neurobiol Aging 1996; 17:385-395.

21 Klaver CC, Ott A, Hofman A, Assink JJ, Breteler MM, de Jong PT: Is age-related maculopathy associated with Alzheimer's disease? The Rotterdam Study. Am J Epidemiol 1999; 150:963-968.

22 Frost S, Guymer R, Aung KZ, Macaulay SL, Sohrabi HR, Bourgeat P, Salvado O, Rowe CC, Ames D, Masters CL, Martins RN, Kanagasingam Y; AIBL Research Group: Alzheimer's disease and the early signs of age-related macular degeneration. Curr Alzheimer Res 2016;13:1259-1266.
23 Kaarniranta K, Salminen A, Haapasalo A, Soininen H, Hiltunen M: Age-related macular degeneration (AMD): Alzheimer's disease in the eye? J Alzheimers Dis 2011;24:615-631.

24 Ohno-Matsui K: Parallel findings in age-related macular degeneration and Alzheimer's disease. Prog Retin Eye Res 2011;30:217-238.

25 McGrory S, Cameron JR, Pellegrini E, Warren C, Doubal FN, Deary IJ, Dhillon B, Wardlaw JM, Trucco E, MacGillivray TJ: The application of retinal fundus camera imaging in dementia: a systematic review. Alzheimers Dement 2017;6:91-107.

26 Lengyel I, Tufail A, Hosaini HA, Luthert P, Bird AC, Jeffery G: Association of drusen deposition with choroidal intercapillary pillars in the aging human eye. Invest Ophthalmol Vis Sci 2004; 45:2886-2892.

27 Lengyel I, Csutak A, Florea D, Leung I, Bird AC, Jonasson F, Peto T: A population-based ultra-widefield digital image grading study for age-related macular degeneration-like lesions at the peripheral retina. Ophthalmology 2015;122:1340-1347.

28 Kernt M, Kampik A: Imaging of the peripheral retina. Oman J Ophthalmol 2013;6(suppl 1):S32-S35

29 Silva PS, Cavallerano JD, Haddad NMN, Kwak H, Dyer KH, Omar AF, Shikari H, Aiello LM Sun JK, Aiello LP: Peripheral lesions identified on ultrawide field imaging predict increased risk of diabetic retinopathy progression over 4 Years. Ophthalmology 2015;122:949-956.

-30 The Writing committee for the OPERA Study; Domalpally A, Clemons TE, Danis PR, Sadda SR, Cukras CA, Toth CA, et al: Peripheral retinal changes associated with age-related macular degeneration in the Age-Related Eye Disease Study 2. Am Acad Ophthalmol 2017;124:479-487.

31 Pellegrini E, Robertson G, Trucco E, MacGillivray TJ, Lupascu C, van Hemert J, Williams MC, Newby DE, van Beek EJR, Houston G: Blood vessel segmentation and width estimation in ultra-wide field scanning laser ophthalmoscopy. Biomed Opt Express 2014;5: 4329-4337. 
32 McKhann G, Drachman D, Folstein M, Katzman R, Price D, Stadlan EM: Clinical diagnosis of Alzheimer's disease: report of the NINCDS-ADRDA Work Group* under the auspices of Department of Health and Human Services Task Force on Alzheimer's Disease. Neurology 1984;34:939.

33 Bird AC, Bressler NM, Bressler SB, Chisholm $\mathrm{IH}$, Coscas G, Davis MD, de Jong PT, Klaver CC, Klein BE, Klein R, et al: An international classification and grading system for age-related maculopathy and age-related macular degeneration. The International ARM Epidemiological Study Group. Surv Ophthalmol 1995;39:367-374.

-34 Croft DE, van Hemert J, Wykoff CC, Clifton D, Verhoek M, Fleming A, Brown DM: Precise montaging and metric quantification of retinal surface area from ultra-wide field fundus photography and fluorescein angiography. Ophthalmic Surg Lasers Imaging Retina 2014;45:312-317.

35 Frost S, Kanagasingam Y, Sohrabi H, Vignarajan J, Bourgeat $P$, Salvado O, Villemagne V, Rowe CC, Macaulay SL, Szoeke C, Ellis KA, Ames D, Masters CL, Rainey-Smith S, Martins RN, Group AR: Retinal vascular biomarkers for early detection and monitoring of Alzheimer's disease. Translat Psychiatry 2013;3:e233.

36 Lisowska A, Annunziata R, Loh GK, Karl D, Trucco E: An experimental assessment of five indices of retinal vessel tortuosity with the RET-TORT public dataset. Proceedings of the 36th Annual International Conference of the IEEE EMBS; 2014, pp 5414-5417; Chicago, IL, USA.
37 Wong TY, Klein R, Sharrett AR, Duncan BB, Couper DJ, Tielsch JM, Klein BE, Hubbard LD: Retinal arteriolar narrowing and risk of coronary heart disease in men and women. The Atherosclerosis Risk in Communities Study. JAMA 2002;287:1153-1159.

38 Roca-Santiago HM, Lago-Bouza JR, MillanCalenti JC, Gomez-Ulla-Irazazabal F: Alzheimer's disease and age-related macular degeneration. Arch Soc Esp Oftalmo 2006;81: 73-78.

39 de Jong FJ, Schrijvers EM, Ikram MK, Koudstaal PJ, de Jong PT, Hofman A, Vingerling JR, Breteler MM: Retinal vascular caliber and risk of dementia: the Rotterdam Study. Neurology 2011;76:816-821.

40 Williams MA, Silvestri V, Craig D, Passmore AP, Silvestri G: The prevalence of age-related macular degeneration in Alzheimer's disease. J Alzheimers Dis 2014;42:909-914.

41 Bonilha VL: Age and disease-related structural changes in the retinal pigment epithelium. Clin Ophthalmol 2008;2:413-424.

42 Williams MA, McGowan AJ, Cardwell CR, Cheung CY, Craig D, Passmore P, Silvestri G, Maxwell AP, McKay GJ: Retinal microvascular network attenuation in Alzheimer's disease; in: Alzheimer's \& Dementia: Diagnosis, Assessment and Disease Monitoring 1. Elsevier, 2015, pp 229-235.
3 Crystal HA, Holman S, Lui YW, Baird AE, Yu H, Klein R, Rojas-Soto DM, Gustafson DR, Stebbins GR: Association of the fractal dimension of retinal arteries and veins with quantitative brain MRI measures in HIV-infected and uninfected women. PLoS One 2016;11:e0154858.

44 Obara K, Meyer JS, Mortel KF, Muramatsu K: Cognitive declines correlate with decreased cortical volume and perfusion in dementia of Alzheimer type. J Neurol Sci 1994;127:96102.

45 Juottonen K, Lehtovirta M, Helisalmi S, Sr PJR, Soininen H: Major decrease in the volume of the entorhinal cortex in patients with Alzheimer's disease carrying the apolipoprotein E $\varepsilon 4$ allele. J Neurol Neurosurg Psychiatry 1998;65:322-327.

46 Risacher SL, Saykin AJ: Neuroimaging biomarkers of neurodegenerative diseases and dementia. Semin Neurol 2013;33:386-416.

-47 Liu C-C, Kanekiyo T, Xu H, Bu G: Apolipoprotein $\mathrm{E}$ and Alzheimer disease: risk, mechanisms, and therapy. Nat Rev Neurol 2013;9: 106-118.

48 Koychev I, Gunn RN, Firouzian A, Lawson J, Zamboni G, Ridha B, Sahakian BJ, Rowe JB, Thomas A, Rochester L, Ffytche D, Howard $\mathrm{R}$, Zetterberg H, MacKay C, Lovestone S: PET tau and amyloid-beta burden in mild Alzheimer's disease: divergent relationship with age, cognition, and cerebrospinal fluid biomarkers. J Alzheimers Dis 2017;60:283-293.

49 Ritchie CW, Ritchie K: The PREVENT study: a prospective cohort study to identify mid-life biomarkers of late-onset Alzheimer's disease. BMJ Open 2012;2:e001893.
Peripheral Retinal Imaging Biomarkers for Alzheimer's Disease: A Pilot Study 